\title{
Effect of a 6-week strength-training program on neuromuscular efficiency in type 2 diabetes mellitus patients
}

\author{
Citation for published version (APA):
}

Shahrjerdi, S., Bahrpeyma, F., Savelberg, H. H. C. M., \& Mohajeri-Tehrani, M. R. (2020). Effect of a 6week strength-training program on neuromuscular efficiency in type 2 diabetes mellitus patients. Diabetology International, 11(4), 376-382. https://doi.org/10.1007/s13340-020-00432-y

\section{Document status and date:}

Published: 01/10/2020

DOI:

10.1007/s13340-020-00432-y

\section{Document Version:}

Publisher's PDF, also known as Version of record

\section{Document license:}

Taverne

Please check the document version of this publication:

- A submitted manuscript is the version of the article upon submission and before peer-review. There can be important differences between the submitted version and the official published version of record. People interested in the research are advised to contact the author for the final version of the publication, or visit the DOI to the publisher's website.

- The final author version and the galley proof are versions of the publication after peer review.

- The final published version features the final layout of the paper including the volume, issue and page numbers.

Link to publication

\footnotetext{
General rights rights.

- You may freely distribute the URL identifying the publication in the public portal. please follow below link for the End User Agreement:

www.umlib.nl/taverne-license

Take down policy

If you believe that this document breaches copyright please contact us at:

repository@maastrichtuniversity.nl

providing details and we will investigate your claim.
}

Copyright and moral rights for the publications made accessible in the public portal are retained by the authors and/or other copyright owners and it is a condition of accessing publications that users recognise and abide by the legal requirements associated with these

- Users may download and print one copy of any publication from the public portal for the purpose of private study or research.

- You may not further distribute the material or use it for any profit-making activity or commercial gain

If the publication is distributed under the terms of Article $25 \mathrm{fa}$ of the Dutch Copyright Act, indicated by the "Taverne" license above, 


\title{
Effect of a 6-week strength-training program on neuromuscular efficiency in type 2 diabetes mellitus patients
}

\author{
Samira Shahrjerdi ${ }^{1} \cdot$ Farid Bahrpeyma $^{1} \cdot$ Hans H. C. M. Savelberg ${ }^{2} \cdot$ Mohammad Reza Mohajeri-Tehrani $^{3}$
}

Received: 19 December 2019 / Accepted: 6 March 2020 / Published online: 19 March 2020

(c) The Japan Diabetes Society 2020

\begin{abstract}
Background The neuromuscular system generates human movement. The functional capacity of the neuromuscular system in patients with type 2 diabetes mellitus (T2DM) is decreased and this affects the generation of muscle force. Exercise is recommended as an effective treatment in such cases. Short-duration strength training causes neural adaptations in healthy participants, but the effects of strength training on T2DM are unclear. The present study aimed to evaluate the effect of strength training on neuromuscular efficiency of lower limb muscles in T2DM.

Methods Surface electromyograms (SEMG) of the knee flexors and extensors were recorded during isometric contractions. The ratio of peak torque to SEMG amplitude was calculated as neuromuscular efficiency. Measurements were taken before the intervention after 6 weeks of non-training, and after 6 weeks of strength training.

Results SEMG amplitudes did not differ among the subsequent measurement sessions. Flexor and extensor peak torque increased after the strength-training program. The neuromuscular efficiency of all muscles increased after the 6 weeks of strength training.

Conclusion A 6-week strength-training program increased the neuromuscular efficiency and peak torque in patients with T2DM; however, the electrical properties of the muscles did not change. These results may be related to increased neural adaptations and motor learning in the early stages of strength training.
\end{abstract}

Keywords Type 2 diabetes mellitus $\cdot$ Muscle strength $\cdot$ Surface electromyography $\cdot$ Isokinetic

\section{Introduction}

Movements in humans are controlled by the neuromuscular system. Using motor unit activation, the neuromuscular system transfers neural signals to muscle fibers and leads to muscle contraction and force generation [1]. Force production and movement are the final outputs of the neuromuscular system [2]. Pathophysiological alterations of the

Farid Bahrpeyma

bahrpeyf@modares.ac.ir

1 Department of Physical Therapy, Faculty of Medical Science, Tarbiat Modares University, Tehran, Iran

2 Department of Nutrition and Movement Science, Faculty of Health, Medicine and Life Sciences, Maastricht University, Maastricht, The Netherlands

3 Endocrinology and Metabolism Research Center, Endocrinology and Metabolism Clinical Sciences Institute, Tehran University of Medical Sciences, Tehran, Iran neuromuscular system caused by diseases or aging lead to impaired force generation and movement [3].

Type 2 diabetes mellitus (T2DM) is associated with impaired neuromuscular system structure and function $[4$, 5]. Neuromuscular dysfunction in T2DM could be attributed to the pathophysiological effects of hyperglycemia on the nerves and muscles. Decreased functional capacity of the neuromuscular system in T2DM has been reported [5]. T2DM leads to impaired motor neuron properties including reduced firing rates and altered motor neuron excitability [6]. T2DM has been associated with neuromuscular defects that contribute to reduced muscle strength [5]. Physical activity and exercise have been emphasized to improve neuromuscular performance and independent living in older adults with T2DM $[4,9]$. Sacchetti et al. show that trained T2DM patients have less neuromuscular impairment than sedentary healthy participants [4].

The functional state of the neuromuscular system could be characterized by its ability to generate a certain degree of muscle activation called "neuromuscular efficiency" [7]. 
Neuromuscular efficiency could be quantified as the ratio of produced force to the amplitude of the bioelectric signals of the muscles [8]. The amplitude of the bioelectric activity of the muscles can be assessed by surface electromyography (SEMG) signals, which reflect the peripheral and central strategies of neuromuscular systems, particularly during muscle contraction and force production [9]. The correlation between force and SEMG signals refers to neuromuscular system expenditures during force generation and movement [10]. Some musculoskeletal diseases including osteoarthritis [11], chronic neck pain [12], anterior cruciate ligament injury [8], or fatigue [13] or even aging [14] may lead to neuromuscular system deficiencies. Decreased efficiency of the neuromuscular system in elderly individuals results in impaired locomotion and physical disability [15]. Exercise training can improve neuromuscular system performance and efficiency in healthy [7] and elderly [16] individuals, but its effects among T2DM patients has not been well documented.

The strength-training programs lead to numerous metabolic advantages in T2DM, including improved muscle mass, quality, strength, and power [5]. Castaneda et al. reported that a 16-week progressive strength-exercise program leads to increased muscle strength in patients with T2DM. Similarly, a 16-week progressive strength-exercise program caused a $42 \%$ increase in upper-extremity muscle strength and a $28 \%$ increase in lower-extremity muscle strength [17]. Larose et al. reported a $65 \%$ increase in knee extensor strength after a 6-month progressive strength-training program [18].

Strengthening exercise causes neuromuscular and morphological adaptations in healthy and elderly participants [19]. Increased muscle strength is partly related to structural adaptations in the muscles which resulting from the long-term effects of strength training; while, neural adaptations contribute to improved muscle strength, particularly in the early stages [20]. Understanding the nature of these neural adaptations is important for optimizing training and rehabilitation protocols for patients with T2DM. Increased muscle strength in T2DM has been reported after various types and durations of strengthtraining programs [21]. Hence, here we hypothesized that T2DM patients, due to their defective neuromuscular systems, may exhibit a specific adaptation pattern in the early stages of strength training. In the present study, we aimed to investigate the effect of a short-term (6 weeks) strength-training program on the lower-limb muscle force generation and neuromuscular properties of T2DM patients.

\section{Methods}

\section{Participants}

Thirteen T2DM patients aged 40-60 years participated in this study. The demographic characteristics of all T2DM

patients is presented in Table 1. In all participants, T2DM was diagnosed 4-10 years prior by an endocrinologist. All patients used oral medications to control the diabetes. No changes in medications occurred during the study period. None of the participants had central or peripheral neurological or orthopedic diseases, retinopathy, foot ulcers, renal failure, hepatic, respiratory or cardiovascular diseases, or thyroid disorders. None of the participants had a history of regular and professional exercise during the previous 6 months. All participants had a fasting blood sugar $100-150 \mathrm{mg} / \mathrm{dL}$, oral glucose tolerance test result $>200 \mathrm{mg} /$ $\mathrm{dL}$, and glycated hemoglobin of 7-9\%. All participants scored between 4 and 7 on the Michigan questionnaire. There was no history of drug or alcohol addiction or smoking. Participants who were unwilling to continue the exercise and test or failed to complete the training program were excluded. Patients who took medication affecting their basal metabolic rate or total body water content like insulin, diuretics, anti-depressants, or blood cholesterol-lowering drugs were excluded from the study. If autonomic neuropathy symptoms emerged during tests or exercise, the participants were excluded. All participants signed an informed consent form. The study was approved by the Medical Ethics Committee of Tarbiat Modares University on 18-01-2018 (approval number: IR.TMU.REC.1395.507).

\section{Study design}

This study had a self-controlled design in which T2DM patients acted as their own control by the division of the study into two 6-week periods [22]. In the first 6-week period, participants performed their own normal activities (control period). During the second period, a 6-week strength-training program was applied (intervention period). All participants were tested at three stages: before the control period, at the end of the control period, and immediately before the intervention period. The intraclass correlation coefficient (ICC) test was used to evaluate the reliability of the results between the first and second test sessions. This design allowed us to reassess the results after the 6-week control period. The protocol is approved

Table 1 Characteristics of T2DM patients

\begin{tabular}{ll}
\hline Characteristics & Mean \pm SD \\
\hline Age (years) & $55 \pm 4.48$ \\
Height $(\mathrm{m})$ & $167.00 \pm 8.21$ \\
Weight $(\mathrm{kg})$ & $79.38 \pm 11.50$ \\
BMI $\left(\mathrm{kg} / \mathrm{m}^{2}\right)$ & $28.29 \pm 3.31$ \\
Female $(\%)$ & $53.84 \%$ \\
Male $(\%)$ & $46.15 \%$ \\
\hline
\end{tabular}

$S D$ standard deviation, $B M I$ body mass index 
by the Iranian registry of clinical trials (approval no. IRCT20180216038744N1).

\section{Strength training protocol}

For 6 weeks, on three non-consecutive days per week, all participants followed a strength-training program involving the knee flexors and extensors, hip abductors and adductors, and calf muscles. The strength-training program was conducted using exercise machines (Technogym 2010). All trainings were supervised by an expert physiotherapist. Prior to the strength training protocol, all participants followed a warm-up program. The strength training protocol in this study was based on the reverse pyramid training method and consisted of three sets of repetitions. The first set was $80 \%$ of one repetition maximum (1RM) of six repetitions. The second set was done with eight repetitions at 70\% of 1RM. The final set was 12 repetitions at $60 \%$ of 1RM. A 90 -s rest was provided between sets. The blood glucose concentration and blood pressure were recorded before and after each training session and the heart rate was monitored during the exercise.

\section{Measurements}

The primary outcome of this study is to clarify the effect of 6-week strength-training program on neuromuscular efficiency of the knee flexor and extensor muscles in T2DM patients. The neuromuscular efficiency was measured based on the amplitudes of SEMG signals during submaximal torques production.

\section{Isometric submaximal torque evaluation}

Knee flexor and extensor isometric torques of the dominant leg were evaluated using an isokinetic dynamometer (HUMAC NORM 2009). The tests included assessing isometric knee flexion and extension moment at $65^{\circ}$ of knee flexion (full extension of the knee joint represented $0^{\circ}$ ).

The tests were performed with the participants seated. Adjustment of the dynamometer seat was specific for each participant. The axis of rotation of the isokinetic dynamometer was aligned with the frontal axis of the knee. The ankle pad was placed precisely above the lateral malleolus. First, for each subject, the maximal voluntary contraction (MVC) of the isometric knee flexors and extensors at $65^{\circ}$ was determined. During the tests, the participants were asked to reach $80 \%$ of the MVC by visual feedback. The test protocol included five isometric contractions at $80 \%$ MVC.

\section{Surface electromyography evaluation}

SEMG is a non-invasive method that quantifies the bioelectric activity of muscles. Although several limitations have been reported for SEMG recording [23], this method is safer, more applicable, more cost-effective, and more tolerable by patients than needle electromyography (EMG) during maximal force production and movement [24]. The accuracy of the SEMG method is reportedly $75-91 \%$ [25]. SEMG activity of the knee flexor muscles (medial hamstrings and lateral hamstring) and knee extensor muscles (vastus medialis obliques, vastus lateralis, and rectus femoris) was recorded concurrent with the isometric evaluation of knee flexion and extension. A bipolar multichannel SEMG amplifier (Bayamed Co.; https://www.bayamed.com 2016) was used to record the SEMG activity. The placement areas were shaved and abraded by alcohol, and a pair of disposable $\mathrm{Ag}-\mathrm{Ag} /$ $\mathrm{Cl}$ electrodes was positioned at 20 -mm interelectrode distances on the muscular belly parallel with the muscle fiber orientation according to surface electromyography for the non-invasive assessment of muscles recommendations. The ground electrode was attached to the lateral malleolus of the other leg.

The raw SEMG signals were recorded at a sampling frequency of $1000 \mathrm{~Hz}$ during force production of the isometric contraction. A bandpass filter with low and high cut-off frequencies of 20 and $500 \mathrm{~Hz}$, respectively, was applied. The on and off times of muscle activation were determined based on two standard deviations of the mean value of the baseline amplitude. The normalized root mean square (RMS) value of the SEMG signals of the knee flexor and extensor muscle during isometric contraction was calculated and considered the amplitude indicator. The average normalized RMS value of five repetitions was considered the SEMG output.

\section{Neuromuscular efficiency}

The neuromuscular efficiency was calculated by dividing the isometric peak torque of the knee flexor or extensor muscles by the RMS of the SEMG signal of each muscle separately.

Neuromuscular efficiency $=\frac{\text { Isometric peak torque }}{\text { RMS }}$

\section{Data analysis}

All data are presented as mean and standard error. To evaluate the reliability of peak torques and SEMG signals between the first and second evaluation sets, the ICC test was performed. The statistical analyses were conducted using SPSS version 16.0 (SPSS, Inc., Chicago, IL, USA) and Medcalc version 8. To determine the normal distribution of the collected data, the Kolmogorov-Smirnov test was used. Friedman's test and the Bonferroni post hoc test were used to identify the differences between the three sessions of 
measurements in T2DM patients. The significant limit was considered $P<0.05$.

\section{Results}

Eight female and five male participants with a mean age of $55.0 \pm 6.4$ years were included. All participants were diagnosed with T2DM 4-10 $(7.1 \pm 2.2)$ years prior. The ICC test between the first and second measurement stages of the peak torque of the knee extensors and flexors and the RMS of the flexors and extensors showed high reliability of the measurement method (Table 2).

Over the training period, knee flexor isometric peak torque $(P<0.05)$ and knee extensor isometric peak torque $(P<0.05)$ increased significantly. Knee extensor and flexor isometric peak torque increased significantly by about 20 and $10 \mathrm{Nm}$, respectively, during the training period (comparing the second and third evaluation phases) (Table 3).
SEMG activity of the knee joint extensor and flexor muscles did not differ significantly between the test sessions (Table 4).

The neuromuscular efficiency of all muscles improved significantly as a function of the strength-training program (Table 5).

\section{Discussion}

The present study aimed to evaluate the effect of short-term strength training on the neuromuscular properties of the knee flexor and extensor muscles in T2DM patients. The main result represented that a 6-week strength-training program led to increased neuromuscular efficiency of the knee extensor and flexor muscles in patients with T2DM. In addition, the knee flexor and extensor isometric peak torques increased; while, the SEMG amplitudes of the knee flexor and extensor muscles remained unchanged after training.

Table 2 ICC of RMS and peak torques between the first and second evaluation sets

\begin{tabular}{llllllll}
\hline & RMS of VMO & RMS of VL & RMS of RF & RMS of MH & RMS of BF & Knee extensor peak torque & Knee flexor peak torque \\
\hline ICC & 0.91 & 0.97 & 0.98 & 0.98 & 0.99 & 0.92 & 0.96 \\
\hline
\end{tabular}

$R M S$ root mean square, $V M O$ vastus medialis oblique, $V L$ vastus lateralis, $R F$ rectus femoris, $M H$ medial hamstring, $B F$ biceps femoris

Table 3 Knee extensor and flexor peak torques

\begin{tabular}{lclllll}
\hline & $\begin{array}{l}\text { First test session } \\
\text { before control period } \\
\text { Mean } \pm \text { Std. Error }\end{array}$ & $\begin{array}{l}\text { Second test session } \\
\text { before training } \\
\text { Mean } \pm \text { Std. Error }\end{array}$ & $\begin{array}{l}\text { Third test session } \\
\text { after training } \\
\text { Mean } \pm \text { Std. } \\
\text { Error }\end{array}$ & Friedman test & $P$ value & $\begin{array}{l}\text { Post hoc analysis } \\
P \text { value }\end{array}$ \\
\cline { 3 - 7 } & & & 1 1st and 2nd & $\begin{array}{l}\text { 1st and 3rd } \\
\text { test sessions }\end{array}$ & $\begin{array}{l}\text { 2nd and 3rd } \\
\text { test sessions } \\
\text { test sessions }\end{array}$ \\
\hline Extensor PT & $142.41 \pm 19.17$ & $144.30 \pm 18.06$ & $162.84 \pm 35.77$ & $0.04^{*}$ & 0.67 & $0.01^{*}$ \\
Flexor PT & $93.07 \pm 16.53$ & $93.3 \pm 16.55$ & $105.76 \pm 16.35$ & $0.01^{*}$ & 0.75 & $0.01^{*}$ \\
\hline
\end{tabular}

$P T$ peak torque $(\mathrm{Nm})$

*Significant statistically

Values are mean \pm std error

Table 4 RMS data of knee flexor and extensor muscles

\begin{tabular}{lllll}
\hline & $\begin{array}{l}\text { First test session before } \\
\text { control period } \\
\text { Mean } \pm \text { Std. Error }\end{array}$ & $\begin{array}{l}\text { Second test session } \\
\text { before training } \\
\text { Mean } \pm \text { Std. Error }\end{array}$ & $\begin{array}{l}\text { Third test session } \\
\text { after training } \\
\text { Mean } \pm \text { Std. Error }\end{array}$ & $\begin{array}{l}\text { Friedman test } \\
P \text { value }\end{array}$ \\
\hline RMS VMO & $186.2 \pm 52.34$ & $182.48 \pm 55.6$ & $191.32 \pm 51.26$ & 0.60 \\
RMS VL & $203.91 \pm 44.56$ & $204.09 \pm 46.02$ & $203.37 \pm 49.46$ & 0.75 \\
RMS RF & $166.89 \pm 48.55$ & $168.39 \pm 47.6$ & $175.46 \pm 49.06$ & 0.23 \\
RMS MH & $151.006 \pm 50.23$ & $148.97 \pm 51.27$ & $155.45 \pm 52.83$ & 0.14 \\
RMS BF & $150.74 \pm 51.98$ & $152.03 \pm 49.87$ & $150.44 \pm 49.39$ & 0.31 \\
\hline
\end{tabular}

$R M S$ root mean square, $V M O$ vastus medialis oblique, $V L$ vastus lateralis, $R F$ rectus femoris, $M H$ medial hamstring, $B F$ biceps femoris

Values are mean \pm std error 
Table 5 Neuromuscular efficiency of knee flexor and extensor muscles

\begin{tabular}{|c|c|c|c|c|c|c|c|}
\hline & \multirow{2}{*}{$\begin{array}{l}\text { First test session } \\
\text { before control period } \\
\text { Mean } \pm \text { Std. Error }\end{array}$} & \multirow{2}{*}{$\begin{array}{l}\text { Second test session } \\
\text { before training } \\
\text { Mean } \pm \text { Std. Error }\end{array}$} & \multirow{2}{*}{$\begin{array}{l}\text { Third test session } \\
\text { after training } \\
\text { Mean } \pm \text { Std. } \\
\text { Error }\end{array}$} & \multirow[t]{2}{*}{$\begin{array}{l}\text { Friedman test } \\
(P \text { value })\end{array}$} & \multicolumn{3}{|c|}{$\begin{array}{l}\text { Post hoc analysis } \\
P \text { value }\end{array}$} \\
\hline & & & & & $\begin{array}{l}\text { 1st and 2nd } \\
\text { test sessions }\end{array}$ & $\begin{array}{l}\text { 1st and 3rd } \\
\text { test sessions }\end{array}$ & $\begin{array}{l}\text { 2nd and 3rd } \\
\text { test sessions }\end{array}$ \\
\hline NME VMO & $0.78 \pm 0.11$ & $0.83 \pm 0.08$ & $0.95 \pm 0.08$ & $0.000^{*}$ & 0.99 & 0.16 & $0.00 *$ \\
\hline NME VL & $0.67 \pm 0.28$ & $0.71 \pm 0.27$ & $0.85 \pm 0.22$ & $0.000 *$ & 0.99 & 0.06 & $0.00 *$ \\
\hline NME RF & $0.87 \pm 0.47$ & $0.96 \pm 0.38$ & $1.09 \pm 0.33$ & $0.003 *$ & 0.99 & 0.22 & $0.01 *$ \\
\hline NME MH & $0.73 \pm 0.33$ & $0.71 \pm 0.31$ & $0.78 \pm 0.31$ & $0.001 *$ & 0.83 & 0.06 & $0.02 *$ \\
\hline NME BF & $0.70 \pm 0.25$ & $0.68 \pm 0.27$ & $0.79 \pm 0.30$ & $0.000 *$ & $0.00 *$ & 0.54 & $0.00^{*}$ \\
\hline
\end{tabular}

$V M O$ vastus medialis oblique, $V L$ vastus lateralis, $R F$ rectus femoris, $M H$ medial hamstring, $B F$ biceps femoris

*Significant statistically

Values are mean \pm std error

The peak torque is the most important parameter during the maximal isometric contraction that specifies muscle force production [26]. The amplitude parameters of SEMG signals such as RMS can estimate the myoelectric activity of muscles [27]. A similar pattern of changes was reported between the peak torques and the RMS of the knee flexor and extensor muscles during maximal isometric contraction in patients with T2DM $[28,29]$. The present study results showed that the RMS of the knee flexor and extensor muscles and the corresponding peak torques showed incongruous patterns of changes after training. These findings suggest that a 6-week strength-training program may modify the relationship between peak torque and RMS during maximal isometric contraction.

Muscle strength increasing after a period of training supports the findings of previous studies [30,31], although variability was seen in training types, durations, and intensities [32]. The duration of the strength training program is a determining factor for training-induced adaptations [33]. The increased muscle strength after a short-term strengthtraining program in the present study may be attributed to the effect of neural adaptions including motor unit recruitment, rate coding, synchronization, reflex propagation, and agonist/antagonists interaction [20] in T2DM patients.

To our knowledge, the present study is the first to investigate the effect of a short-term strength-training program on the neuromuscular properties of the knee extensor and flexor muscles in patients with T2DM. We used the relationship between force and SEMG amplitude to determine neuromuscular efficiency. Botton et al. showed that a 12-week strength training improved maximal strength and muscle thickness in patients with T2DM. Knee extensor muscle quality and rapid strength did not significantly increase in this study due to suitable glycemic control and the absence of neuropathy in the T2DM population of this study [31]. Bazzucchi stated that a 16-week strength- and endurance-training program improved the muscle torques and muscle fiber conduction velocity (MFCV) during the isometric contraction of the knee extensors in patients with T2DM. Bazzucchi et al. suggested that the increased MFCV could be ascribed to the changes in neuromuscular recruitment strategies in T2DM [30].

It is interesting to note that the training-induced increase in neuromuscular efficiency in the present study was due to increased peak torques and non-significant changes in the RMS of the knee flexor and extensor muscles in T2DM. The RMS of force production reflects the neural drive to muscles including firing rates and active motor unit recruitment [20]. Hence, increased neuromuscular efficiency independent of RMS changes may be related to the central mechanism of motor control [20]. Cannon and Cafarelli reported that a force Cannon and Cafarelli reported a force increase with a decrease in IEMG during maximal isometric knee extension after an 8-week strength-training program in healthy male participants. The results are attributed to changes in agonist-antagonist co-activation and variability of neural control in the multi-compartmental quadriceps muscle [34]. In contrast, Garfinkel et al. found that an 8-week strength-training program led to increased force production, an unchanged SEMG amplitude, and an increased cross-sectional area of the knee extensor muscles. The alteration in muscle strength without changes in SEMG amplitude was interpreted as a structural adaptation by Garfinkel and Cafarelli, because they observed an increased cross-sectional areas of the knee extensors after strength training [35]. Cadore et al. found that improved synergist co-activation and lower antagonist co-contraction were the main causes of the strength gain and neuromuscular economy in the early stages of strength training in elderly participants [36].

Another possible explanation for the higher neuromuscular efficiency after a 6-week strength-training program could be related to an improved central strategy of movement. T2DM has some deleterious effects on the motor and cognitive function of the brain [37]. Physical activity and 
exercise could attenuate the adverse effects of T2DM on the brain; in particular, resistance exercise can improve brain function in patients with T2DM [38]. Improved interneuron synaptic efficiency in the central nervous system [39], increased synchronizations, and an improved antagonist/ agonist interaction [20] may be possible mechanisms for increased neuromuscular efficiency in the early stages of strength training without obvious changes in EMG amplitude. Hence, T2DM patients at the early stages of strength training learn to optimally produce force with better coordination and synchronization.

This study potentially demonstrates the concept of the neuromuscular system in T2DM and the use of strength training applications to increase neuromuscular system efficiency. Some limitations to the generalization of these results should be considered. First, the SEMG data may have been altered by methodological, biomechanical, or physiological factors. Second, controlling the morphological adaptation including the crossover area of the muscles after training may provide better insight about the causes of our findings. Finally, more studies are required to detect the quota of each part of the neuromuscular system to enable maximal force production in patients with T2DM.

In conclusion, we observed that even a short-term strength-training program led to improved muscle strength in T2DM patients. The myoelectric activities of muscles do not contribute to increased muscle strength at the early stage of strength training in T2DM. Thus, the higher neuromuscular efficiency after the 6-week strength-training program in T2DM may be related to a central drive in T2DM patients.

Acknowledgements This study was a residency thesis and was supported by Tarbiat Modares University. The authors would like to thanks the subjects for their participation in this study.

\section{Compliance with ethical standards}

Conflict of interest The authors declare no conflict of interest regarding publication of this manuscript.

\section{References}

1. Moritani T. Neuromuscular adaptations during the acquisition of muscle strength, power and motor tasks. J Biomech. 1993;26(Suppl 1):95-107.

2. Duchateau J, Semmler JG, Enoka RM. Training adaptations in the behavior of human motor units training adaptations in the behavior of human motor units. J Appl Physiol (Bethesda, MD: 1985). 2006;101(6):1766-75.

3. Power GA, Dalton BH, Rice CL. Human neuromuscular structure and function in old age: a brief review. J Sport Health Sci. 2013;2(4):215-26.

4. Sacchetti M, Balducci S, Bazzucchi I, Carlucci F, di Palumbo AS, Haxhi J, et al. Neuromuscular dysfunction in diabetes: role of nerve impairment and training status. Med Sci Sports Exerc. 2013;45(1):52-9.

5. Orlando G, Balducci S, Bazzucchi I, Pugliese G, Sacchetti M. Neuromuscular dysfunction in type 2 diabetes: underlying mechanisms and effect of resistance training. Diabetes/Metab Res Rev. 2016;32(1):40-50.

6. Watanabe K, Gazzoni M, Holobar A, Miyamoto T, Fukuda $\mathrm{K}$, Merletti R, et al. Motor unit firing pattern of vastus lateralis muscle in type 2 diabetes mellitus patients. Muscle Nerv. 2013;48(5):806-13.

7. David P, Mora I, Pérot C. Neuromuscular efficiency of the rectus abdominis differs with gender and sport practice. J Strength Cond Res. 2008;22(6):1855-61.

8. Aragão FA, Schäfer GS, de Albuquerque CE, Vituri RF, de Azevedo FM, Bertolini GRF. Neuromuscular efficiency of the vastus lateralis and biceps femoris muscles in individuals with anterior cruciate ligament injuries. Revis Bras Ortop. 2015;50(2):180-5.

9. Farina D, Merletti R, Enoka RM. The extraction of neural strategies from the surface EMG. J Appl Physiol (Bethesda, MD: 1985). 2004;96(4):1486-95.

10. Arabadzhiev TI, Dimitrov VG, Dimitrova NA, Dimitrov GV. Interpretation of EMG integral or RMS and estimates of "neuromuscular efficiency" can be misleading in fatiguing contraction. J Electromyogr Kinesiol. 2010;20(2):223-32.

11. Patsika G, Kellis E, Amiridis IG. Neuromuscular efficiency during sit to stand movement in women with knee osteoarthritis. J Electromyogr Kinesiol. 2011;21(5):689-94.

12. Falla D, Jull G, Edwards S, Koh K, Rainoldi A. Neuromuscular efficiency of the sternocleidomastoid and anterior scalene muscles in patients with chronic neck pain. Disabil Rehabil. 2004;26(12):712-7.

13. Milner-Brown HS, Mellenthin M, Miller RG. Quantifying human muscle strength, endurance and fatigue. Arch Phys Med Rehabil. 1986;67(8):530-5.

14. Schimidt HL, Machado ÁS, Vaz MA, Carpes FP. Isometric muscle force, rate of force development and knee extensor neuromuscular efficiency asymmetries at different age groups. Revis Bras Cineantropometria Desempenho Hum. 2014;16:307-15.

15. Reid KF, Pasha E, Doros G, Clark DJ, Patten C, Phillips EM, et al. Longitudinal decline of lower extremity muscle power in healthy and mobility-limited older adults: influence of muscle mass, strength, composition, neuromuscular activation and single fiber contractile properties. Eur J Appl Physiol. 2014;114(1):29-39.

16. Cadore EL, Pinto RS, Pinto SS, Alberton CL, Correa CS, Tartaruga MP, et al. Effects of strength, endurance, and concurrent training on aerobic power and dynamic neuromuscular economy in elderly men. J Strength Cond Res. 2011;25(3):758-66.

17. Castaneda C, Layne JE, Munoz-Orians L, Gordon PL, Walsmith $\mathrm{J}$, Foldvari M, et al. A randomized controlled trial of resistance exercise training to improve glycemic control in older adults with type 2 diabetes. Diabetes Care. 2002;25(12):2335-411.

18. Larose J, Sigal RJ, Boule NG, Wells GA, Prud'homme D, Fortier MS, et al. Effect of exercise training on physical fitness in type II diabetes mellitus. Med Sci Sports Exerc. 2010;42(8):1439-47.

19. Reeves ND, Narici MV, Maganaris CN. Effect of resistance training on skeletal muscle-specific force in elderly humans. J Appl Physiol (Bethesda, MD: 1985). 2004;96(3):885-92.

20. Gabriel DA, Kamen G, Frost G. Neural adaptations to resistive exercise: mechanisms and recommendations for training practices. Sports Med (Auckland, NZ). 2006;36(2):133-49.

21. Hovanec N, Sawant A, Overend TJ, Petrella RJ, Vandervoort AA. Resistance training and older adults with type 2 diabetes mellitus: strength of the evidence. J Aging Res. 2012; https://doi. org/10.1155/2012/284635. 
22. Louis TA, Lavori PW, Bailar JC, Polansky M. Crossover and self-controlled designs in clinical research. N Engl J Med. 1984;310(1):24-31.

23. Farina D, Cescon C, Merletti R. Influence of anatomical, physical, and detection-system parameters on surface EMG. Biol Cyber. 2002;86(6):445-56.

24. Carlo JDL. The use of surface electromyography in biomechanics. J Appl Biomech. 1997;13(2):135-63.

25. De Luca CJ, Adam A, Wotiz R, Gilmore LD, Nawab SH. Decomposition of surface EMG signals. J Neurophysiol. 2006;96(3):1646-57.

26. Davir Z. Isokinetic muscle testing interpertation and clinical applications. London: Churchill Livingstone; 2004.

27. Vigotsky AD, Halperin I, Lehman GJ, Trajano GS, Vieira TM. Interpreting signal amplitudes in surface electromyography studies in sport and rehabilitation sciences. Front Physiol. 2018;8:985.

28. Hatef B, Ghanjal A, Meftahi GH, Askary-Ashtiani A. Isokinetic and electromyographic properties of muscular endurance in short and long-term type 2 diabetes. Glob J Heal Sci. 2016;8(8):54366.

29. Hatef B, Bahrpeyma F, Mohajeri Tehrani MR. The comparison of muscle strength and short-term endurance in the different periods of type 2 diabetes. J Diabet Metab Disord. 2014;13(1):22.

30. Bazzucchi I, De Vito G, Felici F, Dewhurst S, Sgadari A, Sacchetti M. Effect of exercise training on neuromuscular function of elbow flexors and knee extensors of type 2 diabetic patients. J Electromyogr Kinesiol. 2015;25(5):815-23.

31. Botton CE, Umpierre D, Rech A, Pfeifer LO, Machado CLF, Teodoro JL, et al. Effects of resistance training on neuromuscular parameters in elderly with type 2 diabetes mellitus: a randomized clinical trial. Exp Gerontol. 2018;113:141-9.

32. Arakawa S, Watanabe T, Sone H, Tamura Y, Kobayashi M, Kawamori R, et al. The factors that affect exercise therapy for patients with type 2 diabetes in Japan: a nationwide survey. Diabetol Int. 2015;6(1):19-25.

33. Mangine GT, Hoffman JR, Gonzalez AM, Townsend JR, Wells AJ, Jajtner AR, et al. The effect of training volume and intensity on improvements in muscular strength and size in resistancetrained men. Physiol Rep. 2015;3(8):e12472.

34. Cannon RJ, Cafarelli E. Neuromuscular adaptations to training. J Appl Physiol (Bethesda, MD: 1985). 1987;63(6):2396-402.

35. Garfinkel S, Cafarelli E. Relative changes in maximal force, EMG, and muscle cross-sectional area after isometric training. Med Sci Sports Exerc. 1992;24(11):1220-7.

36. Cadore EL, Pinto SS, Alberton CL, Pinto RS, Baroni BM, Vaz MA, Lanferdini FJ, Radaelli R, González-Izal M, Bottaro M, Kruel LFM. Neuromuscular adaptations to concurrent training in the elderly: effects of intrasession exercise sequence. Age. 2013;35:891-903.

37. Guerrero-Berroa E, Ravona-Springer R, Heymann A, Schmeidler J, Silverman JM, Sano M, et al. Decreased motor function is associated with poorer cognitive function in elderly with type 2 diabetes. Dement Geriatr Cognit Disord Extra. 2014;4(1):103-12.

38. Yi SS. Effects of exercise on brain functions in diabetic animal models. World J Diabetes. 2015;6(4):583-97.

39. Uno K. Roles of the interorgan neuronal network in the development of metabolic syndrome. Diabetol Int. 2016;7(3):205-11.

Publisher's Note Springer Nature remains neutral with regard to jurisdictional claims in published maps and institutional affiliations. 